\title{
The Green Product's Pricing Strategy in a Dual Channel considering Manufacturer's Risk Attitude
}

\author{
Junjie Ma, ${ }^{1}$ Wenchao $\mathrm{Yu}^{2}{ }^{2}$ Shuxia $\mathrm{Li}^{2}{ }^{2}$ Linghong Zhang $\mathbb{D}^{2}{ }^{2}$ and Shaobin Zang ${ }^{1}$ \\ ${ }^{1}$ School of Law, Tongji University, Shanghai 200092, China \\ ${ }^{2}$ School of Business, Shandong Normal University, Jinan 250014, China \\ Correspondence should be addressed to Linghong Zhang; 614104@sdnu.edu.cn
}

Received 13 November 2020; Revised 3 June 2021; Accepted 21 June 2021; Published 1 July 2021

Academic Editor: Wei Zhang

Copyright (c) 2021 Junjie Ma et al. This is an open access article distributed under the Creative Commons Attribution License, which permits unrestricted use, distribution, and reproduction in any medium, provided the original work is properly cited.

This paper develops a two-echelon green supply chain that consists of one green manufacturer and one retailer. The green manufacturer has both online direct and offline retail channels. Considering manufacturer's risk attitude and product's green level, the paper constructs centralized and decentralized game models when the online channel's demand is uncertain. Furthermore, this paper analyzes the impacts of a set of factors, including consumer environmental awareness (CEA), product green level, and risk attitude on decision-making in the supply chain. Finally, we present numerical examples. The main findings are as follows: the manufacturer and the retailer will benefit from the improvement of CEA; hence, they could invest more to obtain more profits by improving CEA; manufacturer's risk attitude has a negative impact on the pricing and profits of the supply chain; as such, the members of the supply chain should improve the accuracy of their demand forecast, so as to minimize risks and losses resulting from uncertainty in demand.

\section{Introduction}

Many manufacturers have begun to produce environmentally friendly products (green products) facing the government regulations as well as international green barriers. Now consumers are more willing to pay for the green product. An empirical survey demonstrates that $62 \%$ of consumers are willing to buy high-star appliances, and half of the consumers are willing to pay $\$ 67.6$ more for purchasing air conditioners with a high energy efficiency level in India [1, 2].

At the same time, with the convenience of online sales, many green product manufacturers develop their own online channels to directly sell their products to the end consumers [3], such as Dell, Media, and Haier. However, introducing the online channel may not mean that the manufacturer's utility will increase because of the channel competition and fluctuation of the online channel demand [4]. Therefore, whether the green manufacturer will benefit from the online channel and how risk attitude affects the dual-channel pricing decision are the questions calling for studies.
Our research is motivated by the household appliances industry. Take Haier as an example, Haier produces a variety of energy-saving air conditioners and refrigerators. At the same time, Haier introduces the online direct channel. Media and Dell are other good examples. With the practice of these green products, it is important to explore the optimal decisions for the manufacturers and retailers. This study focuses on how a manufacturer that sells a green product can take advantage of both the traditional retail channel and the direct online channel.

The demand of the online channel could be affected by some nonproduct or service-related factors such as Internet accessibility and consumers' acceptance that may be difficult to observe [5]. With the uncertain demand, the risk attitude suggested by prior studies is an important factor affecting a firm's decision [6]. Hence, with the uncertainty of the online demand, in this paper, we will explore the price strategies changes when the manufacturer's risk attitude is different.

Specifically, we investigate the following research questions: (1) How the manufacturer and the retailer decide the online direct price and the retail price to mitigate 
channel conflict? (2) How the demand uncertainty and manufacturer's risk attitude influence manufacturer and retailer's decisions?

To answer these questions, we consider a dual-channel green supply chain, where one manufacturer produces a green product and sells the product through a retail channel and its own direct channel to maximize his profit. Considering CEA and the demand uncertainty, we give the demand functions of the online channel and retail channel. In the Stackelberg game, we assume that the manufacturer is the leader and the retailer is the follower, and we discuss the scenarios when the manufacturer is risk neutral and risk averse in the centralized model and decentralized model, respectively. In the centralized model, the manufacturer and the retailer as a whole decide the green product's online channel price and retail channel price. In the decentralized model, the dominant manufacturer decides the wholesale price and online channel price; then the retailer decides the retail price. We use the backward induction to solve the problem. In addition, we conduct numerical studies to observe the profit changes with respect to key parameters. Finally, we give the main managerial implications.

The rest of the paper is organized as follows. In Section 2, we present the literature review. In Sections 3 and 4, we establish the centralized model and decentralized model when the manufacturer is risk neutral and risk averse. Section 5 presents the numerical examples. We conclude this study in Section 6.

\section{Literature Review}

There are some literature related to green supply chain, dual channel, and risk attitude, and we here primarily review the most related two research streams: dual channel and risk attitude.

The first stream focuses on how the manufacturer or the retailer coordinates the two channels to mitigate the channel competition. Tsay and Agrawal [7] developed a model that captured key attributes of such a setting, including various sources of inefficiency. Yao and Liu [8] considered the price competition between these two channels under two market game settings: the Bertrand and the Stackelberg price competition models. Yue and Liu [9] analyzed the benefits of sharing demand forecast information in a manufacturerretailer supply chain. Cai et al. [10] evaluated the impact of price discount contracts and pricing schemes with the dualchannel supply chain competition. Dan et al. [11] evaluated the impacts of retail services and the degree of customer loyalty to the retail channel on the manufacturer and retailer's pricing behaviors in a centralized and a decentralized dual-channel supply chain. Chen and Bell [12] examined how a firm that faces customer returns can enhance profit by using different customer returns policies, full-refund and no-returns, as a device to segment its market into a dual-channel structure. Cao et al. [13] developed an analytical framework to study the impact of an "online-tostore" channel on the demand allocations and profitability of a retailer who sells products to customers through multiple distribution channels. Li et al. [14] examined a dual-channel supply chain in which the manufacturer makes green products for the environmental consciousness. Jamali and Rasti-Barzoki [1] focused on the pricing and determination of the degree of greenness of a product in competition with a nongreen product. Barzinpour and Taki [15] proposed a mathematical model in this paper that identifies locations of productions and shipment quantity by exploiting the tradeoff between costs and emissions for a dual-channel supply chain network. Yang et al. [16] modeled the environmental responsibility behaviors of both manufacturer and consumers to study the dual-channel structure strategy of a green manufacturer and further examines its environmental performance under fuzzy uncertainties. Ranjan and Jha [17] investigated the pricing strategies and coordination mechanisms considering the green quality and sales effort. Li et al. [18] constructed a dual-channel value chain composed of one altruistic manufacturer and one altruistic retailer, where the manufacturer makes green innovation input for green products and sells its green products to its customers through both the direct channel and the traditional channel, and the retailer provides channel service for customers and sells green products through the traditional channel. Liang and Sun [19] considered service free-riding and channel price difference in a green product dual-channel supply chain with a manufacturer and a retailer. Li et al. [20] studied a dynamic price game model in a dual-channel green supply chain considering firm's innovation input of green products and channel service. Lou et al. [21] explored the issues concerning green subsidies of government and optimal decisions of a manufacture and dual-channel retailers in a two-echelon dual-channel supply chain.

The above literature works mainly discuss the pricing for the dual channel, but the uncertainty of the online channel is not considered. This paper will explore the impacts of the uncertainty of online demand on dual-channel pricing.

The second stream focuses on how the supply chain member's risk attitude affects the manufacturer's and retailer's decisions. In the single-channel sales model, Zand et al. [22] studied the profit division of the supply chain members considering their risk attitude and bargaining power through asymmetrical Nash bargaining. Ni et al. [23] analyzed the risk of the manufacturer and the supplier in a scenario in which an upstream supplier and a downstream manufacturer transacting an intermediate product via direct bilateral contracting and futures market channels with differentiated products. Wan et al. [24] focused on uncertain demand from the merchant and agency mode perspectives. In the dual-channel model, $\mathrm{Xu}$ et al. [25] investigated the impact of establishing a dual-channel supply chain coordinating contract when the supply chain agents are risk aversion under a mean-variance model. Li et al. [26] explored the effects of the retailer's risk indicator on the retail price, the ordering quantities of the e-channel and traditional channel and the profits of the supplier and the retailer, and the total profits of the supply chain. Zhu et al. [27] measured the risk attitude with Conditional Value-at-Risk $(\mathrm{CVaR})$ approach and assumed that the manufacturer is risk neutral and the retailer is risk averse in a dual-channel supply chain including a direct channel and a traditional 
channel. Zhang and Wang [4] studied the retailer's risk attitude under the condition that a retailer sells short-lifecycle product and uses the online channel as a supplement to its traditional channel. Rahmani and Yavari [28] investigated the demand disruption management in a dual-channel supply chain producing and selling green products. Wang and Song [29] investigated the pricing policies for dualchannel supply chain under uncertain demand but assumed that the manufacturer is risk neutral, the manufacturer sells green products by the direct channel, and the retailer sells nongreen products.

Most above literature discussed the traditional product's price strategy with retailer's risk attitude, but in this paper, we assume that the online direct channel and the retail channel sell the green product and discuss the scenario when the manufacturer is risk neutral or risk averse.

\section{Assumptions and the Model}

3.1. Problem Description. Assume that a two-echelon green supply chain consists of one manufacturer and one retailer. We assume that the manufacturer produces a green product with green quality $e$. The manufacturer sells the product to the retailer with the wholesale price and sells the product directly to consumers by online direct channel. The retailer sells the product to consumers by retail channel. Consumers choose the sale channel to purchase the product based on their channel preference.

The structure of the dual-channel supply chain is illustrated in Figure 1.

3.2. Assumptions. Compared with the ordinary product, the green product has green quality such as the low carbon emission, energy saving, or the high recycling rate. We denote the green quality of the green product as the green level of the product. We consider the impacts of the CEA and green level of the product on the market demand. As the CEA and the green level of the product increase, the green product's demand increases [22]. And the demand decreases with the retail price. Because the demand of the online channel has much higher uncertainty than the offline channel, hence we assume that the online channel demand is uncertain. Further, we study the risk attitude of the manufacturer in the model.

Similar to $[30,31]$, we assume that the green product's demand functions for the offline sales and direct sales channels are as follows, respectively:

$$
\begin{aligned}
& D_{r}=a_{1}-p_{r}+\theta\left(p_{d}-p_{r}\right)+\tau e, \\
& D_{d}=a_{2}-p_{d}+\theta\left(p_{r}-p_{d}\right)+\tau e+\varepsilon,
\end{aligned}
$$

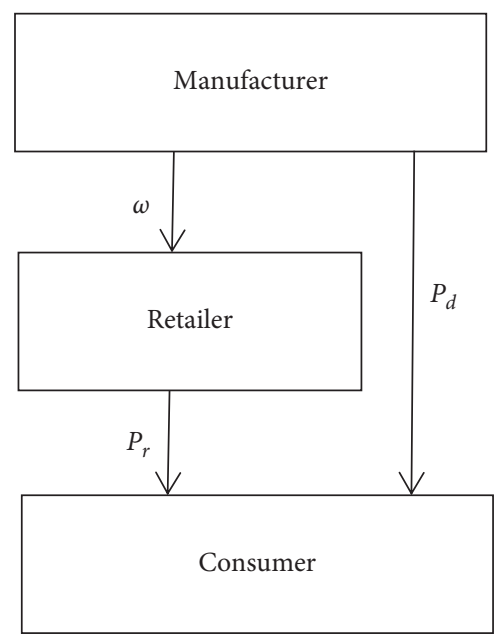

FIGURE 1: Dual-channel supply chain structure.

where $\varepsilon$ is the random demand and follows a truncated normal distribution in $[-A, A], E(\varepsilon)=0$, and $\operatorname{Var}(\varepsilon)=\sigma^{2}$. And, we assume that $\tau e \geq A$ to ensure that the online channel's demand is positive.

Assume that the manufacturer is responsible for the $\mathrm{R} \& \mathrm{D}$ and manufacturing costs of the green product in the supply chain. Similar to Zhu and He [32] and Reimann et al. [33], the manufacturer's $\mathrm{R} \& \mathrm{D}$ cost in the green product is $(1 / 2) z e^{2}$, where $z$ is the R\&D influence coefficient. With the direct sale channel, the marketing cost for the manufacturer is $c_{\mathrm{sm}}$.

We use $\eta_{m}$ to denote the risk attitude of the manufacturer; $\eta_{m}=0$ indicates that the manufacturer is risk neutral and a higher $\eta_{m}$ value indicates that the manufacturer is more risk averse. The parameters and decision variables are presented in Table 1.

Based on the above assumptions, the profit functions for the manufacturer and retailer are derived as follows:

$$
\begin{aligned}
& \pi_{m}=\omega D_{r}+\left(p_{d}-c_{\mathrm{sm}}\right) D_{d}-\frac{1}{2} z e^{2}, \\
& \pi_{r}=\left(p_{r}-\omega\right) D_{r} .
\end{aligned}
$$

The manufacturer's expected profit function is

$$
\begin{aligned}
E\left(\pi_{m}\right) & =E\left\{\omega D r+\left(p_{d}-c_{\mathrm{sm}}\right) D d-\frac{1}{2} z e^{2}\right\} \\
& =\omega\left[a_{1}-p_{r}+\theta\left(p_{d}-p_{r}\right)+\tau e\right]+\left(p_{d}-c_{\mathrm{sm}}\right)\left[a_{2}-p_{d}+\theta\left(p_{r}-p_{d}\right)+\tau e\right]-\frac{1}{2} z e^{2} .
\end{aligned}
$$


TABLE 1: Model parameters and decision variables.

\begin{tabular}{|c|c|}
\hline Parameters & Definition \\
\hline e & Green level of product \\
\hline$c_{\mathrm{sm}}$ & Unit marketing cost of manufacturer \\
\hline$\tau$ & CEA $(\tau>0)$ \\
\hline$a_{i}$ & Market demand of channel $i\left(a_{i}>0\right)$ \\
\hline$z$ & R\&D cost coefficient \\
\hline$\eta_{m}$ & Manufacturer's risk attitude $\left(\eta_{m} \geq 0\right)$ \\
\hline$\varepsilon$ & Uncertainty in demand $\left(\varepsilon \sim N\left(0, \sigma^{2}\right)\right)$ \\
\hline$\sigma^{2}$ & Mean squared error of demand \\
\hline$\theta$ & Cross price elasticity coefficient between traditional sales channel and direct sales channel $(\theta>0)$ \\
\hline$I$ & $i=r$ or $m$ represents the manufacturer or the retailer \\
\hline & The profit of $i$ \\
\hline$E\left(\pi_{i}\right) ; U\left(\pi_{i}\right)$ & The expected profit and the utility of $i$ \\
\hline
\end{tabular}

Decision variables

$\omega$

$p_{r}$

$\underline{p_{d}}$

In addition, superscript $c$ denotes the centralized decision-making model, and superscript $d$ denotes the decentralized decision-making model. Subscripts 1 and 2 denote whether the manufacturer is risk neutral or risk averse, respectively; subscript $d$ denotes the direct sale channel; and subscript $c$ denotes the supply chain.

As the manufacturer is risk averse, based on the meanvariance theory [34] and the impacts of profit and variance, the manufacturer's expected utility is

$$
\begin{aligned}
U\left(E\left(\pi_{m}\right)\right)= & E\left(\pi_{m}\right)-\eta_{m} \operatorname{Var}\left(\pi_{m}\right) \\
& =E\left(\pi_{m}\right)-\eta_{m} E\left[\pi_{m}-E\left(\pi_{m}\right)\right]^{2}=\omega\left[a_{1}-p_{r}+\theta\left(p_{d}-p_{r}\right)+\tau e\right] \\
& +\left(p_{d}-c_{\mathrm{sm}}\right)\left[a_{2}-p_{d}+\theta\left(p_{r}-p_{d}\right)+\tau e\right] \\
& -\frac{1}{2} z e^{2}-\eta_{m}\left(p_{d}-c_{\mathrm{sm}}\right)^{2} \sigma^{2}
\end{aligned}
$$

\section{Centralized Decision Model}

In the centralized model, the manufacturer and the retailer are as a whole, and the goal is to maximize the utility of the supply chain. On this basis, we discuss the two scenarios in which the manufacturer is either risk neutral or risk averse.

In the centralized model, the expected utility of the supply chain is as follows:

$$
\begin{aligned}
U\left(E \pi_{c}^{c}\right)= & U\left(E \pi_{m}\right)+U\left(\pi_{r}\right) \\
= & \left(p_{d}^{c}-c_{\mathrm{sm}}\right)\left[a_{2}-p_{d}^{c}+\theta\left(p_{r}^{c}-p_{d}^{c}\right)+\tau e\right]-\frac{1}{2} z e^{2} \\
& -\eta_{m}\left(p_{d}^{c}-c_{\mathrm{sm}}\right)^{2} \sigma^{2}+p_{r}^{c}\left[a_{1}-p_{r}^{c}+\theta\left(p_{d}^{c}-p_{r}^{c}\right)+\tau e\right] .
\end{aligned}
$$

4.1. Manufacturer Is Risk Neutral. In this section, we study the supply chain's pricing strategy under the centralized decision model when the manufacturer is risk neutral. In this scenario, $\eta_{m}=0$; then, the utility functions of the manufacturer and the supply chain can be derived as follows: 


$$
\begin{aligned}
& U\left(E \pi_{m 1}^{c}\right)=\omega_{1}^{c}\left[a_{1}-p_{r 1}^{c}+\theta\left(p_{d 1}^{c}-p_{r 1}^{c}\right)+\tau e\right]+\left(p_{d 1}^{c}-c_{\mathrm{sm}}\right)\left[a_{2}-p_{d 1}^{c}+\theta\left(p_{r 1}^{c}-p_{d 1}^{c}\right)+\tau e\right]-\frac{1}{2} z e^{2}, \\
& U\left(\pi_{c 1}^{c}\right)=\left(p_{d 1}^{c}-c_{\mathrm{sm}}\right)\left[a_{2}-p_{d 1}^{c}+\theta\left(p_{r 1}^{c}-p_{d 1}^{c}\right)+\tau e\right]-\frac{1}{2} z e^{2}+p_{r 1}^{c}\left[a_{1}-p_{r 1}^{c}+\theta\left(p_{d 1}^{c}-p_{r 1}^{c}\right)+\tau e\right] .
\end{aligned}
$$

Theorem 1. In the centralized decision model, when the manufacturer is risk neutral, the optimal green supply chain pricing strategies for the manufacturer and retailer are as follows:

$$
\begin{aligned}
& p_{d 1}^{c}=\frac{a_{2}+\left(a_{1}+a_{2}\right) \theta+(1+2 \theta)\left(c_{\mathrm{sm}}+\tau e\right)}{2(2 \theta+1)}, \\
& p_{r 1}^{c}=\frac{a_{1}+\left(a_{1}+a_{2}\right) \theta+(1+2 \theta) \tau e}{2(2 \theta+1)} .
\end{aligned}
$$

Proof of Theorem 1 is shown in Appendix A.

From Theorem 1, we can see that the manufacturer's direct sale price and the retailer's retail price are correlated with market demand, the market share of the offline sales channel, CEA, and product green level. From this theorem, Propositions 1-3 can be derived.

Proposition 1. In the centralized decision model, when the manufacturer is risk neutral, both $p_{d 1}^{c}$ and $p_{r 1}^{c}$ increase with CEA $\tau$.

Proposition 2. In the centralized decision model, when the manufacturer is risk neutral, both $p_{d 1}^{c}$ and $p_{r 1}^{c}$ increase with the product green level $e$.
Proposition 1 shows that, with CEA, the manufacturer's and the retailer's channel prices increase; Proposition 2 shows that when the manufacturer increases investment in the $R \& D$ to improve the green level of the green product, both the manufacturer's direct sales price and the retailer's retail price increase.

Proof of Propositions 1 and 2 is shown in Appendix C.

4.2. Manufacturer Is Risk Averse. In this subsection, we study green product's pricing strategies in the centralized decision model when the manufacturer is risk averse. With the uncertain demand of the online channel, the manufacturer's risk attitude may be averse. In this scenario, $\eta_{m}>0$, and the utility function of the supply chain is

$$
\begin{aligned}
U\left(E \pi_{c 2}^{c}\right)= & \left(p_{d 2}^{c}-c_{\mathrm{sm}}\right)\left[a_{2}-p_{d 2}^{c}+\theta\left(p_{r 2}^{c}-p_{d 2}^{c}\right)+\tau e\right] \\
& -\frac{1}{2} z e^{2}-\eta_{m}\left(p_{d 2}^{c}-c_{\mathrm{sm}}\right)^{2} \sigma^{2}+p_{r 2}^{c}\left[a_{1}-p_{r 2}^{c}\right. \\
& \left.+\theta\left(p_{d 2}^{c}-p_{r 2}^{c}\right)+\tau e\right] .
\end{aligned}
$$

Theorem 2. In the centralized decision model, when the manufacturer is risk averse, the optimal pricing strategies for the dual channels of the green supply chain are as follows:

$$
\begin{gathered}
p_{d 2}^{c}=\frac{a_{2}+\left(a_{1}+a_{2}\right) \theta+(1+2 \theta)\left(c_{\mathrm{sm}}+\tau e\right)+2(1+\theta) c_{\mathrm{sm}} \eta_{m} \sigma^{2}}{2\left(2 \theta+\eta_{m} \sigma^{2}+\theta \eta_{m} \sigma^{2}+1\right)}, \\
p_{r 2}^{c}=\frac{a_{1}+\left(a_{1}+a_{2}\right) \theta+(1+2 \theta) \tau e+\left(\theta c_{\mathrm{sm}}+a_{1}+\tau e\right) \eta_{m} \sigma^{2}}{2\left(2 \theta+\eta_{m} \sigma^{2}+\theta \eta_{m} \sigma^{2}+1\right)} .
\end{gathered}
$$

Proof of Theorem 2 is shown in Appendix B.

Different from Theorem 1, the prices of both channels in Theorem 2 are related to the variable of the random demand. From this Theorem 2, Propositions 3-5 can be derived.

Proposition 3. In the centralized decision model, when the manufacturer is risk averse, both $p_{d 1}^{c}$ and $p_{r 1}^{c}$ increase with CEA $\tau$.

Proposition 4. In the centralized decision model, when the manufacturer is risk averse, both $p_{d 2}^{c}$ and $p_{r 2}^{c}$ increase with the product green level $e$.
Similar to Propositions 1 and 2, we could obtain Propositions 3 and 4.

Proposition 5. In the centralized decision model, when the manufacturer is risk averse, $p_{d 2}^{c}$ and $p_{r 2}^{c}$ decrease with the manufacturer's risk averse level $\eta_{m}$.

Proposition 5 means that the higher the manufacturer's risk averse level, the lower the direct sale price and the retail price. It is interesting that the retail price of the offline channel also decreases with $\eta_{m}$.

Proof of Propositions 3 and 4 is shown in Appendix C and proof of Proposition 5 is shown in Appendix D. 


\section{Decentralized Decision Model}

In this model, both the manufacturer and the retailer try to maximize their own utility. In the Stackelberg game, we assume that the manufacturer is the leader and the retailer is the follower. The manufacturer's decision variables are the wholesale price $\omega$ and direct sale price $p_{d}$; the retailer needs to decide the retail price $p_{r}$. We use the backward induction method to determine the optimal solutions. The manufacturer's utility function and retailer's profit function are as follows:

$$
\begin{aligned}
U\left(E \pi_{m}^{d}\right) & =\omega^{d}\left[a_{1}-p_{r}^{d}+\theta\left(p_{d}^{d}-p_{r}^{d}\right)+\tau e\right]+\left(p_{d}^{d}-c_{\mathrm{sm}}\right)\left[a_{2}-p_{d}^{d}+\theta\left(p_{r}^{d}-p_{d}^{d}\right)+\tau e\right]-\frac{1}{2} z e^{2}-\eta_{m}\left(p_{d}^{d}-c_{\mathrm{sm}}\right)^{2} \sigma^{2} \\
\pi_{r}^{d} & =\left(p_{r}^{d}-\omega^{d}\right) D_{r}=\left(p_{r}^{d}-\omega^{d}\right)\left[a_{1}-p_{r}^{d}+\theta\left(p_{d}^{d}-p_{r}^{d}\right)+\tau e\right] .
\end{aligned}
$$

5.1. Manufacturer Is Risk Neutral. In this subsection, we study the pricing strategy under the decentralized decision model when the manufacturer is risk neutral; that is, $\eta_{m}=0$.
Then the utility functions of the manufacturer, retailer, and the whole supply chain can be derived as follows:

$$
\begin{gathered}
U\left(E \pi_{m 1}^{d}\right)=\omega_{1}^{d}\left[a_{1}-p_{r 1}^{d}+\theta\left(p_{d 1}^{d}-p_{r 1}^{d}\right)+\tau e\right]+\left(p_{d 1}^{d}-c_{\mathrm{sm}}\right)\left[a_{2}-p_{d 1}^{d}+\theta\left(p_{r 1}^{d}-p_{d 1}^{d}\right)+\tau e\right]-\frac{1}{2} z e^{2}, \\
U\left(\pi_{r 1}^{d}\right)=\left(p_{r 1}^{d}-\omega_{1}^{d}\right)\left[a_{1}-p_{r 1}^{d}+\theta\left(p_{d 1}^{d}-p_{r 1}^{d}\right)+\tau e\right] \\
U\left(E \pi_{c 1}^{d}\right)=\left(p_{d 1}^{d}-c_{\mathrm{sm}}\right)\left[a_{2}-p_{d 1}^{d}+\theta\left(p_{r 1}^{d}-p_{d 1}^{d}\right)+\tau e\right]-\frac{1}{2} z e^{2}+p_{r 1}^{d}\left[a_{1}-p_{r 1}^{d}+\theta\left(p_{d 1}^{d}-p_{r 1}^{d}\right)+\tau e\right] .
\end{gathered}
$$

Theorem 3. In the decentralized decision model, when the manufacturer is risk neutral, the optimal pricing strategies for the green supply chain for the manufacturer and retailer are as follows:

$$
\begin{aligned}
& p_{d 1}^{d}=\frac{a_{2}+\left(a_{1}+a_{2}\right) \theta+(1+2 \theta)\left(c_{\mathrm{sm}}+\tau e\right)}{2(2 \theta+1)}, \\
& \omega_{1}^{d}=\frac{a_{1}+\left(a_{1}+a_{2}\right) \theta+(1+2 \theta) \tau e}{2(2 \theta+1)}, \\
& p_{r 1}^{d}=\frac{2 \theta(1+\theta)\left(a_{1}+a_{2}\right)+a_{1}(3+4 \theta)+\theta c_{\mathrm{sm}}(1+2 \theta)+[3+4 \theta(2+\theta)] \tau e}{8 \theta^{2}+12 \theta+4} .
\end{aligned}
$$

Proof of Theorem 3 is shown in Appendix E.

Theorem 3 indicates that, in the decentralized decision model, when the manufacturer is risk neutral, the wholesale price, direct sales price, and retail price are correlated with market demand, the market share of the offline sales channel, CEA, and product green level. From Theorem 3, Propositions 6 and 7 can be derived.

Proposition 6. In the decentralized decision model, when the manufacturer is risk neutral, $p_{d 1}^{d}, \omega_{1}^{d}$, and $p_{r 1}^{d}$ increase with CEA.

Proposition 7. In the decentralized decision model, when the manufacturer is risk neutral, $p_{d 1}^{d}, \omega_{1}^{d}$, and $p_{r 1}^{d}$ increase with product green level.
Proof of Propositions 6 and 7 is shown in Appendix H. Propositions 6 and 7 indicate that high CEA motivates the manufacturer to increase input into $R \& D$ and manufacturing of the green product; a high green level requires higher-quality raw materials and more input into advertising and marketing. The extra costs will eventually be shifted to consumers, driving up the price.

5.2. Manufacturer Is Risk Averse. In this subsection, we consider supply chain pricing strategies in the decentralized decision model when the manufacturer is risk averse $\left(\eta_{\mathrm{m}}>0\right)$. Then the utility functions of the manufacturer, retailer, and the whole supply chain can be derived as follows: 


$$
\begin{gathered}
U\left(E \pi_{m 2}^{d}\right)=\omega_{2}^{d}\left[a_{1}-p_{r 2}^{d}+\theta\left(p_{d 2}^{d}-p_{r 2}^{d}\right)+\tau e\right]+\left(p_{d 2}^{d}-c_{\mathrm{sm}}\right)\left[a_{2}-p_{d 2}^{d}+\theta\left(p_{r 2}^{d}-p_{d 2}^{d}\right)+\tau e\right]-\frac{1}{2} z e^{2}-\eta_{m}\left(p_{d 2}^{d}-c_{\mathrm{sm}}\right)^{2} \sigma^{2} \\
U\left(\pi_{r 2}^{d}\right)=\left(p_{r 2}^{d}-\omega_{2}^{d}\right) D_{r}=\left(p_{r 2}^{d}-\omega_{2}^{d}\right)\left[a_{1}-p_{r 2}^{d}+\theta\left(p_{d 2}^{d}-p_{r 2}^{d}\right)+\tau e\right] .
\end{gathered}
$$

The expected utility of the supply chain is

$$
\begin{array}{r}
U\left(E \pi_{c 2}^{d}\right)=\left(p_{d 2}^{d}-c_{\mathrm{sm}}\right)\left[a_{2}-p_{d 2}^{d}+\theta\left(p_{r 2}^{d}-p_{d 2}^{d}\right)+\tau e\right] \\
-\frac{1}{2} z e^{2}+p_{r 2}^{d}\left[a_{1}-p_{r 2}^{d}+\theta\left(p_{d 2}^{d}-p_{r 2}^{d}\right)+\tau e\right]-\eta_{m}\left(p_{d 2}^{d}-c_{\mathrm{sm}}\right)^{2} \sigma^{2}
\end{array}
$$

Theorem 4. In the decentralized decision model, when the manufacturer is risk averse, the optimal pricing strategies for the green supply chain are as follows:

$$
\begin{aligned}
& p_{d 2}^{d}=\frac{a_{2}+\left(a_{1}+a_{2}\right) \theta+(1+2 \theta)\left(c_{\mathrm{sm}}+\tau e\right)+2(1+\theta) c_{\mathrm{sm}} \eta_{m} \sigma^{2}}{2\left(2 \theta+\eta_{m} \sigma^{2}+\theta \eta_{m} \sigma^{2}+1\right)}, \\
& \omega_{2}^{d}=\frac{a_{1}+\left(a_{1}+a_{2}\right) \theta+(1+2 \theta) \tau e+\left(\theta c_{\mathrm{sm}}+a_{1}+\tau e\right) \eta_{m} \sigma^{2}}{2\left(2 \theta+\eta_{m} \sigma^{2}+\theta \eta_{m} \sigma^{2}+1\right)}, \\
& p_{r 2}^{d}=\frac{a_{1}(4 \theta+3)+2 \theta(1+\theta)\left(a_{1}+a_{2}\right)+\theta(1+2 \theta) c_{\mathrm{sm}}+\left(3+8 \theta+4 \theta^{2}\right) \tau e+3(1+\theta)\left[\theta c_{\mathrm{sm}}+a_{1}+\tau e\right] \eta_{m} \sigma^{2}}{4(\theta+1)\left(2 \theta+\eta_{m} \sigma^{2}+\theta \eta_{m} \sigma^{2}+1\right)} .
\end{aligned}
$$

Proof of Theorem 4 is shown in Appendix F.

Theorem 4indicates that, under the decentralized decision model, when the manufacturer is risk averse, the direct sales price, the wholesale price, and the retail price are correlated with market demand, the market share of the offline sales channel, CEA, and the manufacturer's risk averse level. Different from Theorem 3, the prices in Theorem 4 are affected by the random demand variable. From Theorem 4, Propositions 8-10 can be derived.

Proposition 8. In the decentralized decision model, when the manufacturer is risk averse, $p_{d 2}^{d}, \omega_{2}^{d}$, and $p_{r 2}^{d}$ increase with CEA.

Proposition 9. In the decentralized decision model, when the manufacturer is risk averse, $p_{d 2}^{d}, \omega_{2}^{d}$, and $p_{r 2}^{d}$ increase with the product green level.

Proof of Propositions 8 and 9 is shown in Appendix G.

Similar to the situations in Propositions 8 and 9, stronger CEA and a high product green level motivate the manufacturer to increase input into $R \& D$ and the procurement of higher-quality green materials. The increases in costs will increase the wholesale price, direct sales price, and retail price.

Proposition 10. In the decentralized decision model, when the manufacturer is risk averse, $p_{d 2}^{d}, \omega_{2}^{d}$, and $p_{r 2}^{d}$ decrease with the manufacturer's risk averse level $\eta_{m}$.

Proof of Proposition 10 is shown in Appendix H.

Proposition 10 indicates that the manufacturer will reduce the investment of the R\&D of the green product as the risk averse level increases; hence, the wholesale price and the direct sales price decrease; then the retailer follows the manufacturer's pricing strategy and reduces the offline sales price.

\section{Numerical Analysis}

In this section, we will present the change trends of the manufacturer's and retailer's profits as market share of the offline sales channel, CEA, product green level, and manufacturer's risk aversion level when the manufacturer is risk 


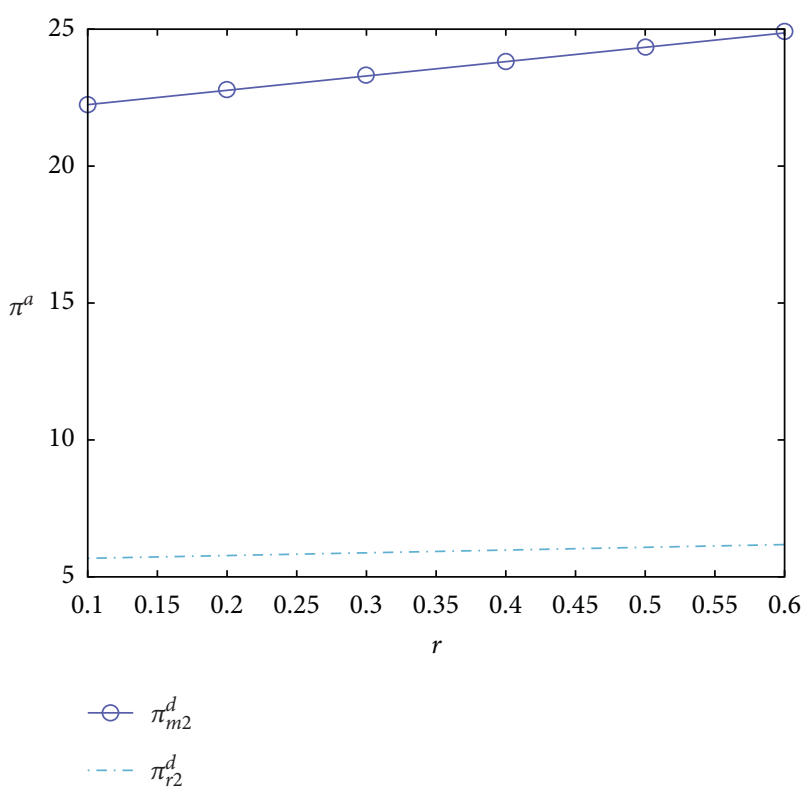

FIgURE 2: Impacts of CEA on profits in the centralized and decentralized decision models.

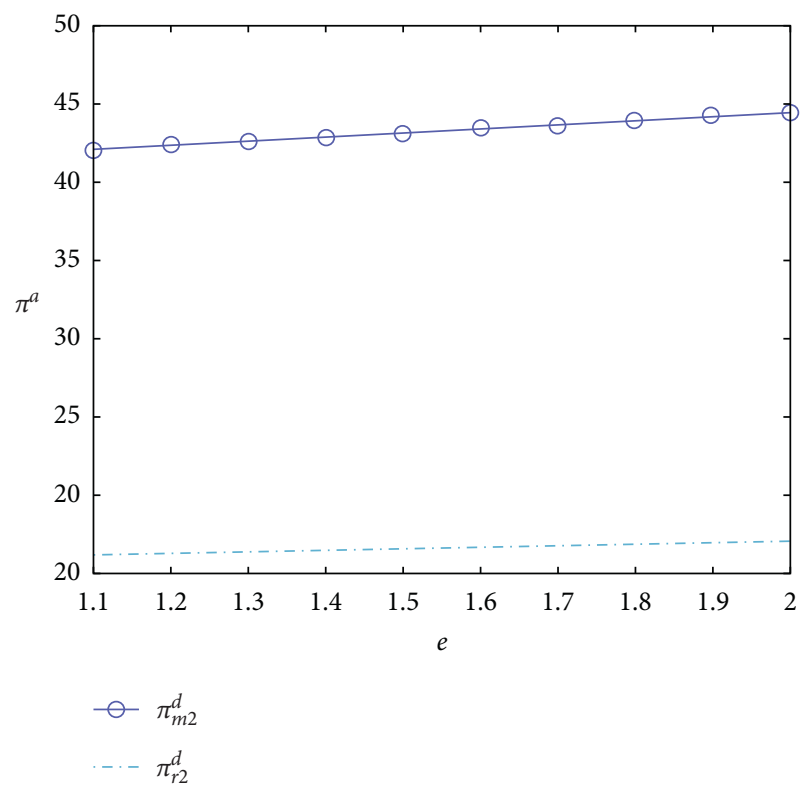

FIGURE 3: Impacts of green level of the product on profits in the centralized and decentralized decision models.

averse in the decentralized model. Because of the complexity of the profits' expressions, we could not give the proofs of the change trends, but we also could obtain some interesting results from the numerical examples. Assume that $c_{\mathrm{sm}}=3$, $z=0.1, \sigma=2$, and $\theta=0.4$. These parameters are consistent with our assumptions and industrial practices.

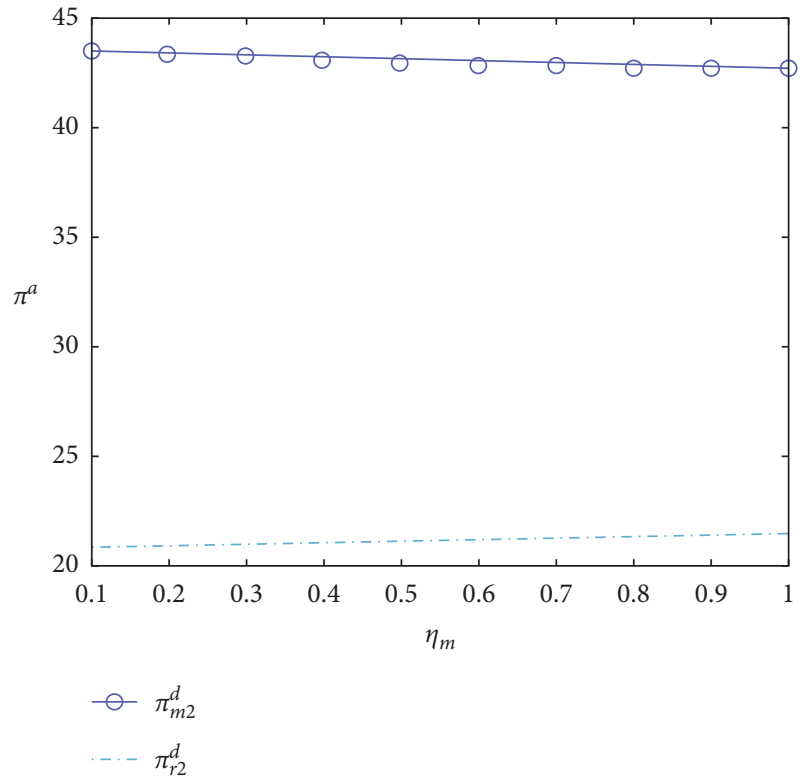

FIGURE 4: Impacts of manufacturer's risk averse level on profits in the centralized and decentralized decision models.

6.1. Impacts of CEA and Green Level of the Product. In this subsection, we explore the impacts of consumers' environmental awareness $\tau$ and green level of the product $e$ on the manufacturer's and retailer's profits. Let $a_{1}=a_{2}=10$, $e=1$, and $\eta_{m}=0.5$, and other parameters are as assumed at the beginning of this section. Figure 2 shows that the manufacturer's and retailer's profits continue to increase with CEA. Figure 3 shows that the manufacturer's and retailer's profits continue to increase with CEA.

Propositions 2, 4, 7, and 9 show that the wholesale price, direct sales price, and retail price increase with $e$. Let $a_{1}=a_{2}=10, \tau=0.5$, and $\eta_{m}=0.5$; we study the green level of the product $e$ on the manufacturer's and retailer's profits. Figure 3 shows that the manufacturer's and retailer's profits continue to increase with $e$. This means that increasing input into green products is profitable, as the profits to members of the supply chain outweigh their input into green products.

6.2. Impact of the Manufacturer's Risk Aversion Level. In this subsection, we explore the impact of manufacturer's risk aversion level $\eta_{m}$ on the manufacturer's and retailer's profits. Assume $a_{1}=a_{2}=10, \tau=0.5$, and $e=1$, and other parameters are as assumed at the beginning of this section. Figure 4 shows the change trends of the manufacturer's and retailer's profits in centralized and decentralized models. Figure 4 shows that the manufacturer's and retailer's profits decrease with $\eta_{m}$ in the centralized model; and the manufacturer's profit decreases but the retailer's profit increases with $\eta_{m}$ in the decentralized model. 


\section{Conclusions}

This paper develops centralized and decentralized decision models in a two-echelon green supply chain that consists of one manufacturer and one retailer. Assume that the manufacturer could open the online direct sale channel and the online demand is uncertain; we analyze the impacts of manufacturer's risk attitude towards the online demand uncertainty on the prices and manufacturer's and retailer's profits. Further, we explore the impacts of the market share of the offline channel, CEA, green level of the product, and manufacturer's risk aversion level. This paper gives the following management insights: manufacturer's high-risk averse level towards the uncertain demand decreases green product's retail price and direct sale price; further, the manufacturer's profit decreases with manufacturer's risk averse level, but retailer's profit may increase with manufacturer's risk averse level. Hence, it may not be a good news to introduce the online channel for the manufacturer when the online channel demand is uncertain and the manufacturer is risk averse. Increasing CEA or green level of the product will bring more profits for the manufacturer and the retailer, thus the manufacturer and the retailer could invest more money on R\&D or advertisement on green product to increase CEA or green level of the product.

This paper only studies a two-echelon green supply chain that consists of one manufacturer and one retailer. In future, we could consider the competition of the manufacturers and retailers. In addition, the differences between the online channel and retail channel are not included. Future research could consider the sale service difference into the model. And the channel coordination contract is another research orient.

\section{Appendix}

\section{A. Proof of Theorem 1}

The following is calculated based on equation (7):

$$
\begin{aligned}
& \frac{\partial U\left(\pi_{c 1}^{c}\right)}{\partial p_{r 1}^{c}}=2\left(p_{d 1}^{c}-p_{r 1}^{c}\right) \theta-2 p_{r 1}^{c}-\theta c_{\mathrm{sm}}+a_{1}+\tau e, \\
& \frac{\partial U\left(\pi_{c 1}^{c}\right)}{\partial p_{d 1}^{c}}=(1+\theta) c_{\mathrm{sm}}+2\left(p_{r 1}^{c}-p_{d 1}^{c}\right) \theta+a_{2}-2 p_{d 1}^{c}+\tau e .
\end{aligned}
$$

The Hessian matrix of $p_{r 1}^{c}$ and $p_{d 1}^{c}$ is $H=\left[\begin{array}{cc}-2 \theta-2 & 2 \theta \\ 2 \theta & -2 \theta-2\end{array}\right]$. Because $\theta>0, \quad|H|=8 \theta+4>0$; furthermore, because $-2 \theta-2<0, U\left(\pi_{c 1}^{c}\right)$ is the concave function of $p_{r 1}^{c}$ and $p_{d 1}^{c} \cdot p_{r 1}^{c}$ and $p_{d 1}^{c}$ have optimal solutions that maximize the utility function of the supply chain.

Let $\left(\partial U\left(\pi_{c 1}^{c}\right) / \partial p_{r 1}^{c}\right)=0$ and $\left(\partial U\left(\pi_{c 1}^{c}\right) / \partial p_{d 1}^{c}\right)=0$; the simultaneous equations are solved to arrive at the optimal solutions of $p_{d 1}^{c}$ and $p_{r 1}^{c}$ which are equations (8) and (9). Theorem 1 is proved.

\section{B. Proof of Theorem 2}

The following is calculated based on equation (10):

$$
\begin{aligned}
\frac{\partial U\left(\pi_{c 2}^{c}\right)}{\partial p_{r 2}^{c}}= & 2 \theta\left(p_{d 2}^{c}-p_{r 2}^{c}\right)-2 p_{r 2}^{c}-\theta c_{\mathrm{sm}}+a_{1}+\tau e, \\
\frac{\partial U\left(\pi_{c 2}^{c}\right)}{\partial p_{d 2}^{c}}= & a_{2}-2 p_{d 2}^{c}+(1+\theta) c_{\mathrm{sm}}+2\left(p_{r 2}^{c}-p_{d 2}^{c}\right) \theta+\tau e \\
& +2\left(c_{\mathrm{sm}}-p_{d 2}^{c}\right) \eta_{m} \sigma^{2} .
\end{aligned}
$$

The Hessian matrix of $U\left(\pi_{c 2}^{c}\right)$ with respect to $p_{r 2}^{c}$ and $p_{d 2}^{c}$ is $H=\left[\begin{array}{cc}-2 \theta-2 & 2 \theta \\ 2 \theta & -2 \eta_{m} \sigma^{2}-2 \theta-2\end{array}\right]$. Because $\theta>0$, $|H|=4(2 \theta+1)+4(1+\theta) \eta_{m} \sigma^{2}>0 ;$ additionally, because $-2 \theta-2<0, H$ is a negative definite matrix, and $U\left(\pi_{c 2}^{c}\right)$ is the concave function of $p_{r 2}^{c}$ and $p_{d 2}^{c}$; therefore, $p_{r 2}^{c}$ and $p_{d 2}^{c}$ have optimal solutions that maximize the utility function of the supply chain. Let $\left(\partial U\left(\pi_{c 2}^{c}\right) / \partial p_{r 2}^{c}\right)=0$ and $\left(\partial U\left(\pi_{c 2}^{c}\right) / \partial p_{d 2}^{c}\right)$ $=0$. The simultaneous equations are solved to arrive at the optimal solutions of $p_{d 2}^{c}$ and $p_{r 2}^{c}$, which are equations (11) and (12). Theorem 2 is proved.

\section{Proofs of Propositions 1-4}

We can obtain Propositions 1-4 by solving the first partial derivative. So we omit the proofs.

\section{Proof of Proposition 5}

The following is calculated based on equations (11) and (12):

$$
\begin{aligned}
& \frac{\partial p_{d 2}^{c}}{\partial \eta_{m}}=-\frac{(1+\theta) \sigma^{2}\left[a_{2}+\left(a_{1}+a_{2}\right) \theta+(1+2 \theta)\left(\tau e-c_{\mathrm{sm}}\right)\right]}{2\left(\eta_{m} \sigma^{2}+\theta \eta_{m} \sigma^{2}+2 \theta+1\right)^{2}}<0, \\
& \frac{\partial p_{r 2}^{c}}{\partial \eta_{m}}=-\frac{\theta \sigma^{2}\left[a_{2}+\left(a_{1}+a_{2}\right) \theta+(1+2 \theta)\left(\tau e-c_{\mathrm{sm}}\right)\right]}{2\left(\eta_{m} \sigma^{2}+\theta \eta_{m} \sigma^{2}+2 \theta+1\right)^{2}}<0 .
\end{aligned}
$$

Therefore, $p_{d 2}^{c}$ and $p_{r 2}^{c}$ are decreasing functions of $\eta_{m}$; namely, with the increase in $\eta_{m}, p_{d 2}^{c}$ and $p_{r 2}^{c}$ decrease. Proposition 5 is proved.

\section{E. Proof of Theorem 3}

The following is calculated based on equation (15):

$$
\frac{\partial U\left(\pi_{r 1}^{d}\right)}{\partial p_{r 1}^{d}}=\theta\left(p_{d 1}^{d}-p_{r 1}^{d}\right)-p_{r 1}^{d}+a_{1}+\tau e-\left(p_{r 1}^{d}-\omega_{r 1}^{d}\right)(\theta+1) .
$$


The second-order partial derivative of $U\left(\pi_{r 1}^{d}\right)$ with respect to $p_{r 1}^{d}$ is $-2 \theta-2<0$; therefore, there is an optimal solution to $p_{r 1}^{d}$ that maximizes (14).

Let $\left(\partial U\left(\pi_{r 1}^{d}\right) / \partial p_{r 1}^{d}\right)=0$; the following can be derived:

$$
p_{r 1}^{d}=\frac{\theta p_{d}+\lambda\left(a_{1}+a_{2}\right)+\tau e+\omega(\theta+1)}{2(\theta+1)} .
$$

Substituting the above equation to equation (14), we have

$$
\begin{aligned}
\max U\left(\pi_{m 1}^{d}\right)= & \frac{1}{2} \omega_{1}^{d}\left[p_{d 1}^{d} \theta-(1+\theta) \omega_{1}^{d}+a_{1}+\tau e\right]-\frac{1}{2} z e^{2} \\
& +\frac{\left(p_{d 1}^{d}-c_{\mathrm{sm}}\right)\left[2\left(a_{1}+a_{2}\right)(1+\theta)-2 a_{1}-2(1+2 \theta) p_{d 1}^{d}+\left(\omega_{1}^{d}-p_{d 1}^{d}\right) \theta^{2}+\left(\omega_{1}^{d}-a_{1}\right) \theta+(2+3 \theta) \tau e\right]}{2(\theta+1)} .
\end{aligned}
$$

Taking the first-order partial derivative of the above equation with respect to $p_{d 1}^{d}$ and $\omega_{1}^{2}$ and rearranging the equation, we have

$$
\begin{aligned}
& \frac{\partial U\left(\pi_{m 1}^{d}\right)}{\partial p_{d 1}^{d}}=\frac{2 a_{2}+2\left(a_{1}+a_{2}\right) \theta+2(1+2 \theta)\left(c_{\mathrm{sm}}-2 p_{d 1}^{d}\right)+\left(c_{\mathrm{sm}}-2 p_{d 1}^{d}+2 \omega_{1}^{d}\right) \theta^{2}+\left(2 \omega_{1}^{d}-a_{1}\right) \theta+(2+3 \theta) \tau e}{2(\theta+1)}, \\
& \frac{\partial U\left(\pi_{m 1}^{d}\right)}{\partial \omega_{1}^{d}}=\theta p_{d 1}^{d}-(1+\theta) \omega_{1}^{d}+\frac{1}{2}\left(a_{1}-\theta c_{\mathrm{sm}}+\tau e\right) .
\end{aligned}
$$

The Hessian matrix of $U\left(\pi_{m 1}^{d}\right)$ wiith respect to $p_{d 1}^{d}$ and $\omega_{1}^{d}$ is $H=\left[\begin{array}{cc}-\left(\left(\theta^{2}+4 \theta+2\right) / \theta+1\right) & \theta \\ \theta & -\theta-1\end{array}\right]$. Because $\theta>0$, $\frac{\partial U\left(\pi_{r 2}^{d}\right)}{\partial p_{r 2}^{d}}=\theta\left(p_{d 2}^{d}-p_{r 2}^{d}\right)-p_{r 2}^{d}+a_{1}+\tau e-\left(p_{r 2}^{d}-\omega_{2}^{d}\right)(\theta+1)$. $|H|=4 \theta+2>0$; additionally, because $-\left(\theta^{2}+4 \theta+2 / \theta+\right.$ $1)<0$, there exist optimal solutions of $p_{d 1}^{d}$ and $\omega_{1}^{d}$ that maximize $U\left(\pi_{m 1}^{d}\right)$.

Let $\left(\partial U\left(\pi_{m 1}^{d}\right) / \partial p_{d 1}^{d}\right)=0$ and $\left(\partial U\left(\pi_{m 1}{ }^{d}\right) / \partial \omega_{1}^{d}\right)=0$; the simultaneous equations are solved to arrive at the optimal solutions of $p_{d 1}^{d}$ and $\omega_{1}^{d}$, which are equations (17) and (18). Substitution of the solutions of $p_{d 1}^{d}$ and $\omega_{1}^{d}$ into $p_{r 1}^{d}$ arrives at equation (19). Theorem 3 is proved.

\section{F. Proof of Theorem 4}

The second-order partial derivative of $U\left(\pi_{r 2}^{d}\right)$ with respect to $p_{r 2}^{d}$ is $-2 \theta-2<0$; therefore, $p_{r 2}^{d}$ has an optimal solution that maximizes $U\left(\pi_{r}\right)$.

Let $\left(\partial U\left(\pi_{r 2}^{d}\right) / \partial p_{r 2}^{d}\right)=0$; solving this equation gives

$$
p_{r 2}^{d}=\frac{\theta p_{d 2}^{d}+a_{1}+\tau e+\omega_{2}^{d}(\theta+1)}{2(\theta+1)} .
$$

Substituting the above equation into equation (20), we have

The following is calculated based on equation (21):

$$
\begin{aligned}
\max U\left(\pi_{m 2}^{d}\right)= & \frac{1}{2} \omega_{2}^{d}\left[p_{d 2}^{d} \theta-(1+\theta) \omega_{2}^{d}+a_{1}+\tau e\right]-\frac{1}{2} z e^{2}-\left(p_{d 2}^{d}-c_{\mathrm{sm}}\right)^{2} \eta_{m} \sigma^{2} \\
& +\frac{\left(p_{d 2}^{d}-c_{\mathrm{sm}}\right)\left[2\left(a_{1}+a_{2}\right)(1+\theta)-2 a_{1}-2(1+2 \theta) p_{d 2}^{d}+\left(\omega_{2}^{d}-p_{d 2}^{d}\right) \theta^{2}+\left(\omega_{2}^{d}-a_{1}\right) \theta+(2+3 \theta) \tau e\right]}{2(\theta+1)} .
\end{aligned}
$$


Taking the first-order partial derivative of the above equation with respect to $p_{d 2}^{d}$ and $\omega_{2}^{d}$ and rearranging the equation, we have

$$
\begin{aligned}
\frac{\partial U\left(\pi_{m 2}^{d}\right)}{\partial p_{d 2}^{d}}= & \frac{2 a_{2}+2\left(a_{1}+a_{2}\right) \theta+2(1+2 \theta)\left(c_{\mathrm{sm}}-2 p_{d 2}^{d}\right)+\left(c_{\mathrm{sm}}-2 p_{d 2}^{d}+2 \omega_{2}^{d}\right) \theta^{2}+\left(2 \omega_{2}^{d}-a_{1}\right) \theta+(2+3 \theta) \tau e}{2(\theta+1)} \\
& +2\left(c_{\mathrm{sm}}-p_{d 2}^{d}\right) \eta_{m} \sigma^{2}, \\
\frac{\partial\left(\pi_{m 2}^{d}\right)}{\partial \omega_{2}^{d}}= & \theta p_{d 2}^{d}-(1+\theta) \omega_{2}^{d}+\frac{1}{2}\left(a_{1}-\theta c_{\mathrm{sm}}+\tau e\right) .
\end{aligned}
$$

The Hessian matrix of $U\left(\pi_{m 2}^{d}\right)$ with respect to $p_{d 2}^{d}$ and $\omega_{2}^{d}$ is $H=\left[\begin{array}{cc}-(2 \theta(\theta+2) / 2 \theta+2)-2 \eta_{m} \sigma^{2}-2 & \theta \\ \theta & -\theta-1\end{array}\right]$. Because $\theta>0,|H|=4 \theta+2(1+\theta) \eta_{m} \sigma^{2}+2>0$; additionally, because $-(2 \theta(\theta+2) / 2 \theta+2)-2 \eta_{m} \sigma^{2}-2<0, p_{d 2}^{d}$ and $\omega_{2}^{d}$ have optimal solutions that maximize $U\left(\pi_{m 2}^{d}\right)$.

Let $\left(\partial U\left(\pi_{m 2}^{d}\right) / \partial p_{d 2}^{d}\right)=0$ and $\left(\partial\left(\pi_{m 2}^{d}\right) / \partial \omega_{2}^{d}\right)=0$. These simultaneous equations are solved to arrive at equations (23) and (24), which are substituted into $p_{r}$ to arrive at equation (25). Theorem 4 is proved.

\section{G. Proofs of Propositions 6-9}

We can obtain Propositions 6-9 by solving the first partial derivative. So we omit the proofs.

\section{H. Proof of Proposition 10}

The following equations are derived based on equations (21) to $(23)$.

$$
\begin{aligned}
& \frac{\partial p_{d 2}^{d}}{\partial \eta_{m}}=-\frac{(\theta+1) \sigma^{2}\left[a_{2}+\left(a_{1}+a_{2}\right) \theta+(1+2 \theta)\left(\tau e-c_{\mathrm{sm}}\right)\right]}{2\left(2 \theta+\eta_{m} \sigma^{2}+\theta \eta_{m} \sigma^{2}+1\right)^{2}}<0, \\
& \frac{\partial \omega_{2}^{d}}{\partial \eta_{m}}=-\frac{\theta \sigma^{2}\left[a_{2}+\left(a_{1}+a_{2}\right) \theta+(1+2 \theta)\left(\tau e-c_{\mathrm{sm}}\right)\right]}{2\left(2 \theta+\eta_{m} \sigma^{2}+\theta \eta_{m} \sigma^{2}+1\right)^{2}}<0, \\
& \frac{\partial p_{r 2}^{d}}{\partial \eta_{m}}=-\frac{\theta \sigma^{2}\left[a_{2}+\left(a_{1}+a_{2}\right) \theta+(1+2 \theta)\left(\tau e-c_{\mathrm{sm}}\right)\right]}{2\left(2 \theta+\eta_{m} \sigma^{2}+\theta \eta_{m} \sigma^{2}+1\right)^{2}}<0 .
\end{aligned}
$$

Therefore, $p_{d 2}^{d}, \omega_{2}^{d}$, and $p_{r 2}^{d}$ are decreasing functions of $\eta_{m}$; that is, as $\eta_{m}$ increases $p_{d 2}^{d}, \omega_{2}^{d}$ and $p_{r 2}^{d}$ decrease. Proposition 10 is proved.

\section{Data Availability}

The data used to support the findings of this study are included within the article.

\section{Conflicts of Interest}

The authors declare that they have no conflicts of interest.

\section{Acknowledgments}

This work was supported by the National Natural Science Foundation of China (Grant nos. 41971252 and 71602103) and the Shanghai University Think Tank Connotation Construction project (Grant no. 2020ZK006).

\section{References}

[1] M.-B. Jamali and M. Rasti-Barzoki, "A game theoretic approach for green and nongreen product pricing in chain-tochain competitive sustainable and regular dual-channel supply chains," Journal of Cleaner Production, vol. 170, pp. 1029-1043, 2018.

[2] M. Jain, A. B. Rao, and A. Patwardhan, "Consumer preference for labels in the purchase decisions of air conditioners in India," Energy for Sustainable Development, vol. 42, pp. 24-31, 2018.

[3] Y. Wang and X. Sun, "Dynamic vs. static wholesale pricing strategies in a dual-channel green supply chain," Complexity, vol. 2019, Article ID 8497070, 14 pages, 2019.

[4] L. Zhang and J. Wang, "Coordination of the traditional and the online channels for a short-life-cycle product," European Journal of Operational Research, vol. 258, pp. 639-651, 2017.

[5] W. Y. K. Chiang, D. Chhajed, and J. D. Hess, "Direct-marketing, indirect profits: a strategic analysis of dual-channel supply-chain design," Management Science, vol. 49, no. 1, pp. 1-20, 2003.

[6] E. Borgonovo and L. Peccati, "Financial management in inventory problems: risk averse vs risk neutral policies," International Journal of Production Economics, vol. 118, no. 1, pp. 233-242, 2009.

[7] A. A. Tsay and N. Agrawal, "Channel conflict and coordination in the E-commerce age," Production and Operations Management, vol. 13, no. 1, pp. 93-110, 2004.

[8] D. Q. Yao and J. J. Liu, "Competitive pricing of mixed retail and e-tail distribution channels," Omega-International Journal of Management Science, vol. 33, no. 3, pp. 235-247, 2005.

[9] X. H. Yue and J. Liu, "Demand forecast sharing in a dualchannel supply chain," European Journal of Operational Research, vol. 174, no. 1, pp. 646-667, 2006.

[10] G. Cai, Z. G. Zhang, and M. Zhang, "Game theoretical perspectives on dual-channel supply chain competition with price the discount s and pricing schemes," International Journal of Production Economics, vol. 117, no. 1, pp. 80-96, 2009. 
[11] B. Dan, G. Y. Xu, and C. Liu, "Pricing policies in a dualchannel supply chain with retail services," International Journal of Production Economics, vol. 139, no. 1, pp. 312-320, 2012.

[12] J. Chen and P. C. Bell, "Implementing market segmentation using full-refund and no-refund customer returns policies in a dual-channel supply chain structure," International Journal of Production Economics, vol. 136, no. 1, pp. 56-66, 2012.

[13] J. Cao, K. C. So, and S. Yin, "Impact of an "online-to-store" channel on demand allocation, pricing and profifitability," European Journal of Operational Research, vol. 248, no. 1, pp. 234-245, 2016.

[14] B. Li, M. Y. Zhu, and Y. S. Jiang, "Pricing policies of a competitive dual-channel green supply chain," Journal of Cleaner Production, vol. 112, pp. 2029-2042, 2016a.

[15] F. Barzinpour and P. Taki, "A dual-channel network design model in a green supply chain considering pricing and transportation mode choice," Journal of Intelligent Manufacturing, vol. 29, pp. 1465-1483, 2018.

[16] D. Y. Yang, T. J. Xiao, and J. Huang, "Dual-channel structure choice of an environmental responsibility supply chain with green investment," Journal of Cleaner Production, vol. 210, pp. 134-145, 2019.

[17] A. Ranjan and J. K. Jha, "Pricing and coordination strategies of a dual-channel supply chain considering green quality and sales effort," Journal of Cleaner Production, vol. 218, pp. 409-424, 2019.

[18] Q. X. Li, X. L. Chen, Y. M. Huang, H. B. Gui, and S. Y. Liu, "The impacts of green innovation input and channel service in a dual-channel value chain," International Journal of Environmental Research and Public Health, vol. 16, 2019.

[19] S. Liang and X. C. Sun, "Product green degree, service freeriding, strategic price difference in a dual-channel supply chain based on dynamic game," Optimization, pp. 1-42, 2020.

[20] Q. X. Li, M. M. Li, and Y. M. Huang, "Dynamic investigation in green supply chain considering channel service," Complexity, vol. 2020, Article ID 1640724, 18 pages, 2020.

[21] Z. K. Lou, X. M. Lou, and X. Z. Dai, "Game-Theoretic models of green products in a two-echelon dual-channel supply chain under government subsidies," Mathematical Problems in Engineering, vol. 2020, Article ID 2425401, 11 pages, 2020.

[22] F. Zand, S. Yaghoubi, and S. J. Sadjadi, "Impacts of government direct limitation on pricing, greening activities and recycling management in an online to offline closed loop supply chain," Journal of Cleaner Production, vol. 215, pp. 1327-1340, 2019.

[23] D. B. Ni, K. W. Li, and X. Fang, "Two-echelon supply chain operations under dual channels with differentiated productivities," International Transactions in Operational Research, vol. 27, pp. 1013-1032, 2020.

[24] X. L. Wan, B. C. Jiang, Q. Q. Li, and X. Q. Hou, "Dual-channel environmental hotel supply chain network equilibrium decision under altruism preference and demand uncertainty," Journal of Cleaner Production, vol. 271, 2020.

[25] G. Y. Xu, B. Dan, B. Zhang, X. M. Zhang, and C. Liu, "Coordinating a dual-channel supply chain with risk-averse under a two-way revenue sharing contract," International Journal of Production Economics, vol. 147, pp. 171-179, 2014.

[26] B. Li, P. W. Hou, P. Chen, and Q. H. Li, "Pricing strategy and coordination in a dual channel supply chain with a risk-averse retailer," International Journal of Production Economics, vol. 178, pp. 154-168, 2016.
[27] L. J. Zhu, X. H. Ren, C. Lee, and Y. M. Zhang, "Coordination contracts in a dual-channel supply chain with a risk-averse retailer," Sustainability, vol. 9, 2017.

[28] K. Rahmani and M. Yavari, "Pricing policies for a dualchannel green supply chain under demand disruptions," Computers \& Industrial Engineering, vol. 127, pp. 493-510, 2019.

[29] L. M. Wang and Q. K. Song, "Pricing policies for dual-channel supply chain with green investment and sales effort under uncertain demand," Mathmatics and Computers in Simulation, vol. 171, pp. 79-93, 2020.

[30] Z. Liu, T. D. Anderson, and J. M. Cruz, "Consumer environmental awareness and competition in two-stage supply chains," European Journal of Operational Research, vol. 218, pp. 602-613, 2012.

[31] L. Zhang, J. Wang, and J. You, "Consumer environmental awareness and channel coordination with two substitutable products," European Journal of Operational Research, vol. 241, pp. 63-73, 2015.

[32] W. Zhu and Y. He, "Green product design in supply chains under competition," European Journal of Operational Research, vol. 258, pp. 165-180, 2016.

[33] M. Reimann, Y. Xiong, and Y. Zhou, "Managing a closed-loop supply chain with process innovation for remanufacturing," European Journal of Operational Research, vol. 276, pp. 510518, 2019.

[34] R. A. Howard, "Decision analysis: practice and promise," Management Science, vol. 34, no. 6, pp. 679-695, 1988. 